\title{
Erratum to: Experimental research on overlying strata movement and fracture evolution in pillarless stress-relief mining
}

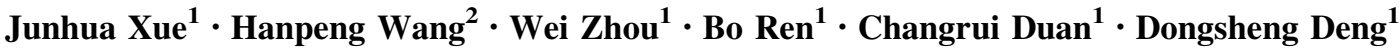

Published online: 19 June 2015

(C) The Author(s) 2015

Erratum to: Int J Coal Sci Technol (2015) 2(1):38-45

DOI 10.1007/s40789-015-0067-0

The original publication of the article contains incorrect Fig. 1. The correct version of Fig. 1 is provided in this erratum.

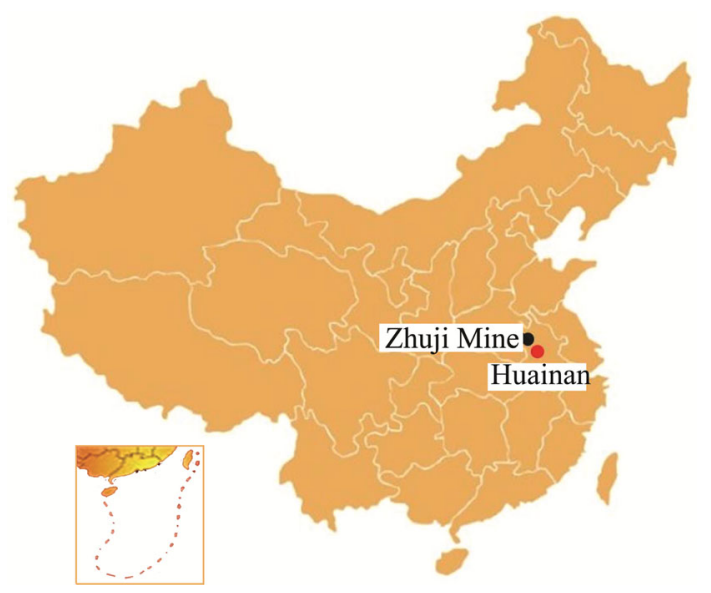

Fig. 1 Zhuji mine in China

The online version of the original article can be found under doi:10.1007/s40789-015-0067-0.

Junhua Xue

xuejunhua2003@163.com

1 State Key Laboratory of Deep Coal Mining \& Environment Protection, Huainan 232001, China

2 Geotechnical \& Structural Engineering Research Center, Shandong University, Jinan 250012, China
Open Access This article is distributed under the terms of the Creative Commons Attribution License which permits any use, distribution, and reproduction in any medium, provided the original author(s) and the source are credited. 